\title{
A atuação, no cenário da escola, limitada por práticas de gestão empresarial
}

\section{The enactment limited by business management practices in the school setting La actuación, en el escenario escolar, limitada por las prácticas de gestión empresarial}

\author{
HENRI DE LEÃO MOTTA \\ Orcid Id: http://orcid.org/0000-0003-3279-5517 \\ Instituto Federal Sul-rio-grandense \\ JAIR JONKO ARAUJO \\ Orcid Id: http://orcid.org/0000-0002-5728-893 \\ Instituto Federal Sul-rio-grandense
}

\begin{abstract}
Resumo: Este artigo objetiva discutir a atuação de professoras de uma escola estadual rural de ensino médio do município de Pelotas/RS no processo de redesenho curricular da política do Ensino Politécnico. Ajustado ao paradigma qualitativo, fundamenta-se na teoria da atuação de Stephen Ball. A produção de dados decorreu do exame documental de e-mails da escola relacionados à construção desta política e do debate, em um grupo focal, com cinco professoras, cujo processo de análise foi organizado a partir da análise textual discursiva. Conclui-se que a política estimulou práticas de gestão empresarial da escola, imbricadas na burocratização e no controle das vozes internas.
\end{abstract}

Palavras-chave: Política educacional. Reconstrução curricular. Ensino Médio.

\begin{abstract}
This article aims to discuss the role of teachers in a rural state high school in the municipality of Pelotas / RS in the process of curricular redesign of the Polytechnic Education policy. Adjusted to the qualitative paradigm, it is based on Stephen Ball's theory of enactment. The production of data resulted from the documentary examination of school emails related to the construction of this policy and from the debate, in a focus group, with five teachers, whose process of analysis was organized from the discursive textual analysis. It is concluded that the policy stimulated school business management practices, intertwined in the bureaucratization and in the control of internal voices.
\end{abstract}

Keywords: Education policy. Curriculum redesign. Secondary school. 
Resumen: Ese articulo presenta como propuesta la discusión de la actuación de las profesoras de una escuela estadual rural de enseñanza secundaria del municipio de Pelotas/RS en el proceso de rediseño curricular de la política de la Enseñanza Politécnica. Ajustado al paradigma cualitativo, se encuentra fundamentación en la teoría de la actuación de Stephen Ball. La producción de datos partió del examen documental de correos electrónicos de la escuela relacionados a la construcción de la politica mencionada, asi como del debate, en un grupo focal, con cinco profesores, cuyo proceso de análisis fue organizado partiéndose del análisis textual discursivo. Por lo tanto, se concluye que la política estimuló prácticas de gestión empresarial de la escuela, imbricadas en la burocratización y en el control de las voces internas.

Palabras clave: Politica educativa. Reconstrucción curricular. Enseñanza secundaria.

\section{INTRODUÇÃO}

No escopo de uma pesquisa realizada no Programa de Pós-Graduação em Educação e Tecnologia do Instituto Federal de Educação, Ciência e Tecnologia Sul-rio-grandense (IFSul - Câmpus Pelotas), o presente artigo refere-se a algumas dimensões que emergiram da compreensão a respeito de como professoras de uma escola estadual, localizada no interior do Município de Pelotas/RS, atuaram a política de Governo denominada "Proposta Pedagógica para o Ensino Médio Politécnico e Educação Profissional Integrada ao Ensino Médio”, desenvolvida entre os anos de 2011 a 2014. Este artigo discute como a reconstrução (ou redesenho) curricular foi circunscrita sob a ótica da gestão empresarial.

A análise engendra-se nas perspectivas da encenação e da recontextualização da política no contexto da prática escolar, tendo como eixo a reflexão de atores escolares sobre sua atuação nesse processo educacional.

Do ponto de vista das políticas de governo, o redesenho curricular do Ensino Médio tem sido alvo de ações que perduram desde os primeiros anos da década de 2000. Encontram-se nesses movimentos alguns indicadores da influência de organismos internacionais na produção de textos políticos, assim como a adoção de princípios norteadores para o chamado Novo Ensino Médio, imbricados em avaliações externas, classificação e distinção meritocrática de sujeitos e instituições. Tal onda reformadora, para além de critérios performáticos, configura-se naquilo que Ball (2004) denomina "governado sem governo", ou seja, a introdução da ideia de responsabilidade (accountability). Ao estudar o Plano de Metas Compromisso Todos pela Educação (TPE) de 2006, Jakimiu (2014) destaca: 
Conforme é possível observar, o TPE emerge em meio a iniciativa empresarial, contexto em que, dada a sua conjuntura, predomina uma concepção de educação nos moldes da perspectiva gerencialista, fundamentadas nos princípios de mercado onde a ênfase da formação recai na eficiência, na eficácia e na produtividade [...]. (p. 50-51).

Em documentos produzidos pela UNESCO e pelo Banco Mundial, entre outras arenas de influência, destilam-se argumentos, como flexibilização curricular, capazes de mediar o redesenho curricular construindo uma narrativa aglutinadora, consensual e adaptativa da cultura escolar ao vocabulário empregado nestes espaços globais, onde conceitos como concorrência e competição constituem a gênese de suas entidades. É o ajustamento da escola às concepções tais como produtividade, eficiência, eficácia, equidade, inclusão e oportunidade, ou seja, um processo de reelaboração de um pensamento hegemônico pela força dos significados, atribuindo aos significantes sentidos que coincidem com a aceitação das mudanças pretendidas com enfoque no mercado.

A força de atração exercida sobre corações e mentes pelas ideias de inclusão, de conhecimento do cotidiano e de certa profissionalidade no Ensino Médio acabam por colaborar na construção de um currículo flexível, a partir de argumentos como a adaptação aos interesses individuais dos alunos e/ou do coletivo local, que de pronto apresentam-se como uma grande conquista, ao tornar o sujeito e/ou o lugar protagonistas da sua própria arquitetura cognitiva. Entretanto, aspectos positivos elencados em relação à flexibilização curricular podem ser problematizados quanto aos atores e quanto aos contextos de influência e de produção de texto político (BOWE; BALL; GOLD, 1992) que, pela construção do poder político num Estado democrático, possibilitam que determinados discursos ligados a interesses particulares sejam operacionalizados como consenso coletivo. Ao estudar o Programa Ensino Médio Inovador (ProEMI), Picoli (2016) ressalta que:

Os macrocampos, embora alguns sejam articulados com as disciplinas dão margem à flexibilização em relação aos conhecimentos ou conteúdos trabalhados para além das disciplinas científicas, de forma a incluir atividades relacionadas à cultura local e ao cotidiano, em detrimento dos conhecimentos científicos sistematizados historicamente pela humanidade. (p. 191).

Em vista disso, a política reconstrutiva dos dispositivos curriculares, ao aderir ao discurso da flexibilidade, transcreve para o espaço da escola necessidades de atuação, de interpretação, de tradução, de recontextualização e, em última análise, 
de aculturação e remodelação de suas estruturas de funcionamento que implicam em reconstrução de identidades: dos professores com sua profissionalidade, dos alunos com o conhecimento e das instituições com a performatividade.

A construção deste artigo articula-se mediante a sustentação do referencial teórico acerca da concepção do conceito de política e seus contextos de influência, de produção de texto e da prática, bem como na análise da atuação de políticas em escolas. $\mathrm{Na}$ sequência, apresentamos os elementos constitutivos das metodologias de prospecção do material empírico e sua releitura a partir de categorias emergentes. Conclui-se este trabalho apresentando análise que orbitou entre as temáticas da atuação, da reconstrução curricular e da perspectiva empresarial no espaço escolar.

\section{A TEORIA DA ATUAÇÃO NA ANÁLISE DE POLÍTICAS POR PERSPECTIVA NÃO CAUSAL}

Ball e Mainardes (2011) destacam que "no Brasil, a pesquisa sobre políticas educacionais vem se configurando com um campo distinto de investigação e em permanente busca de consolidação" (p. 11) e apontam como indicadores deste avanço o aumento das pesquisas, das publicações, dos grupos e das linhas de pesquisa e dos eventos específicos sobre políticas sociais e educacionais. Mais adiante escrevem

\footnotetext{
Nas pesquisas e publicações brasileiras sobre políticas educacionais, observa-se a existência de dois grupos distintos: a) estudos de natureza teórica sobre questões mais amplas do processo de formulação de políticas, abrangendo discussões mais amplas do processo de formulação de políticas, abordagens históricas das políticas educacionais brasileiras (geralmente vinculadas à análise de contextos socioeconômico e político, entre outros aspectos; e b) análise e avaliação de programas e políticas educacionais específicas. (Ibidem, p.12)
}

Ball (1994) afirma que "política é (...) um conjunto de tecnologias e práticas as quais são realizadas e disputadas em nível local. Política é ambos, texto e ação, palavras e fatos, é tanto o que é intencionado como o que é realizado." (Ibidem, p.10, tradução nossa). A partir dessa perspectiva, ao mesmo tempo em que uma política está sendo construída, está sendo contestada e alterada: os "elaboradores" não conseguem controlar o significado de uma determinada política, uma vez que elas serão interpretadas pelos agentes das diferentes arenas/níveis, criando novos significados. Assim, os discursos - e as políticas - são deslocados e relocalizados, produzindo uma mescla de posicionamentos diversos, muitas vezes ambíguos. 
Moreira (2006) também destaca a necessidade que "se as políticas são conjuntos de tecnologias e práticas que se desenrolam, em meio a lutas, em cenários locais, não faz sentido se ficar restrito às deliberações oficiais" (p.267).

Ball enfatiza que não utiliza o termo implementação de políticas, pois entende que políticas não são implementadas de forma linear e hierárquica. Para ele "a ação pode ser coagida ou forçada [...], mas não determinada pela política". (BALL, 1994, p.18). Em outro texto ele chama a atenção para o fato de que "nem todas as organizações incorporam as mudanças com igual boa vontade e entusiasmo" (BALL, 2006, p.16) e, logo, a "análise política necessita ser acompanhada por cuidadosa pesquisa regional, local e organizacional se nos propusermos a entender o grau de 'aplicação' e de 'espaço de manobra', envolvido na tradução das políticas nas práticas” (Ibidem). Salienta, ainda, os riscos das conclusões resultantes de pesquisas focadas em uma única política, como se esta não dialogasse com políticas anteriormente dominantes: "a abordagem da trajetória capta as formas pelas quais as políticas evoluem, se modificam e decaem ao longo do tempo e do espaço, assim como suas incoerências" (Ibidem, p.21).

Tendo por opção estudar política levando em conta essa complexidade, Ball desenvolveu um método heurístico de análise denominado ciclo de políticas, o qual busca capturar a dinâmica da política nos e entre os diferentes níveis de análise, caracterizando-o como um método de pesquisa com abordagem na trajetória política. Esse método tem sido bastante utilizado em análise de políticas educacionais no Brasil (BALL; MAINARDES, 2011).

O autor desenvolveu esse método tendo por princípio que as políticas são construídas em contextos (BOWE; BALL; GOLD, 1992; BALL, 1994). Define, então, três contextos principais de construção de políticas: o de influências (política como discurso), o de produção do texto (política como texto) e o da prática. Estes contextos estão inter-relacionados - não como etapas lineares, não apresentando relação sequencial, nem temporal -, envolvendo arenas, lugares e grupos de interesse, disputas, embates e não há sentido simples de fluxo de informação entre eles.

O contexto de influência é o que legitima as políticas, constituindo o discurso de base e legitimando determinados conceitos; o de produção do texto simboliza a construção dos diferentes textos que representam a política, os quais, em geral, não são internamente coerentes e claros, podendo inclusive ser contraditórios, ao usar significantes de modos diversos; por fim, o contexto da prática é aquele em que as políticas são vivenciadas e produzem efeitos 
e consequências, os quais podem representar mudanças e transformações significativas em relação à política original concebida - é a arena de luta por significados e sentidos, terreno de contestação.

No escopo dessa compreensão, surge posteriormente a Teoria da Atuação (BALL; MAGUIRE; BRAUN, 2016) como resultado de um estudo de caso realizado em quatro escolas secundárias inglesas que examinou o contexto da prática destas escolas, focando na compreensão da interpretação dos professores e outros atores quanto às suas possibilidades de criação ante a limites materiais e discursivos margeados pelas políticas. Relatam os autores

[...]. Em nossas escolas, professores e outros atores de política não estavam simplesmente envolvidos na realização do trabalho de política; ou seja, implementando reformas. Ao contrário, eles estavam envolvidos em processos, em lutas e negociações sobre o que certas políticas significavam, o que poderia ser ou deveria ser feito na prática, como essas interpretações poderiam ser construídas e reconstruídas. O que descobrimos foi que, em todas as nossas quatro escolas do estudo de caso, as políticas foram "personalizadas" e estavam ativas na construção e na reconstrução das identidades profissionais de vários atores de políticas. Assim, as políticas foram atuadas e não implementadas. (Ibidem, p. 10).

Complexa, contextual e interativa, a política é texto, é artefato, é compreendida por tradução e filtro, é especulada individual e coletivamente, é codificada e decodificada (podendo ser ainda recodificada), é deslocamento da abstração do significado genérico e ideal para a concretude do significante local e histórico. Em suas contingências, “[...] a atuação de políticas envolve processos criativos de interpretação e recontextualização [...].” (Ibidem, p. 14), ainda que algumas possam ser dirigidas a atores com menor espaço para a criatividade. Materializada a política no contexto espaço-tempo, estará sempre sujeita ao intemperismo ativo das escolas enquanto um contexto da prática da atuação.

Como se já não bastassem os desafios de operar a política perante um conceito emaranhado, multiforme, multifacetado em redes de interesse e valores, na escola não há política no singular. Além de plurais, ao conjugá-las, são encontradas no passado, no presente e no futuro. Algumas daquelas do passado sequer foram atuadas, enquanto outras - ao serem submetidas aos processos de recodificação e intemperismo escolar - podem ter deixado sua marca "nos corpos e posições dos sujeitos".

A extensão na quantidade de políticas implica em observar a diversidade de temas que convivem no plano escolar. Para os formuladores de política, estando estes atuando no contexto de influência, no contexto de produção de texto ou no contexto da prática enquanto agentes burocráticos, estruturados e estratificados 
nos níveis (local, intermediário ou global), a política pode ser vislumbrada a partir de um viés unitário, de excelência ou de protagonismo inquestionável! Nesse caso, não são percebidos os atores em seu conjunto, as características de seu palco e pouco sabem a respeito dos valores do público que estará a assistir o espetáculo. $\mathrm{Na}$ escola, não existe espaço para a encenação/atuação de um monólogo

Elas [as polítcas] "falam" de formas diferentes para grupos específicos da escola
e para especialistas, disciplinas, ou grupos com a mesma idade e são (às vezes)
encenadas/atuadas de forma diferente dentro da mesma escola por diferentes
atores de políticas [...]. Algumas políticas também se aglomeram para formar
agrupamentos de políticas, conjunto de políticas inter-relacionadas e que
mutuamente se reforçam, que podem, em alguns casos, "sobredeterminar"
a atuação [...]. Algumas colidem ou se sobrepõem, produzindo contradições,
incoerências ou confusão. (Ibidem, p. 19).

Se as escolas podem ser mudadas e, conforme assumimos a partir das discussões desta obra, entendemos que as políticas são feitas pelos e para os professores, que, na escola, somos sujeitos e objetos delas, que elas nos marcam e nós as marcamos. Se as políticas não dizem exatamente o que deve ser feito mas reduzem as opções, a atuação em políticas significa que

[...] colocar as políticas em prática é um processo criativo, sofisticado e complexo. O trabalho com políticas tem seus prazeres, satisfações e seduções e, para alguns, tem benefícios pessoais. As políticas são repletas de emoções e de tensões psicossociais. Elas podem ameaçar ou perturbar a autoestima, o propósito e a identidade. Elas podem entusiasmar, deprimir ou afligir. (Ibidem, p. 21).

As reformas estruturais do Estado assinaladas mais precisamente a partir dos anos 1980 e 1990, sob o argumento central de esgotamento do modelo keynesiano, modificaram a função e a forma como as escolas e professores são percebidos pelos governos, que passaram a atuar segundo concepções de modernização, baseadas na performatividade e na responsabilidade (accountability) (BALL, 2004), e no profissionalismo e gerencialismo (BALL, 2005). A ideia de flexibilização nas funções do Estado nos aproxima daquilo que Ball, Maguire e Braun (2016) ressaltam ao exporem que "O que está sendo exigido das escolas, sua contribuição para a competitividade da economia nacional e coesão cultural, é codificado em uma litania de declarações políticas, documentos e legislações; [...]" (p. 22). Complementam ainda que "A política é fácil, as atuações não são" (p. 22).

Ao encerrar esta seção, reafirmamos os principais conceitos que serão utilizados no estabelecimento da análise do material empírico: o conceito de política - sua extensão e objetivos - o conceito de atuação - como elemento problematizador ao sentido de implementação de política, bem como perceber 
a capacidade criativa dos sujeitos, as marcas coletivas e individuais na relação intérprete/texto político e na relação instituição/texto político - e o conceito de ciclo de políticas - operacionalizado pelo trinômio influência/produção/prática - e sua imbricação à burocracia do Estado.

\section{METODOLOGIAS DE PROSPECÇÃO E DE ANÁLISE}

Compreendendo a relevância dos significados construídos mediante a exposição ao texto, uma vez que pretendemos abordar o critério semântico no desenvolvimento de nossa análise embasados em Moraes e Galiazzi (2013), fundamentamos a preferência pela palavra prospecção para indicar um mergulho no material empírico. Também simbolizamos o material prospectado como artefato com amparo nas ideias de Ball, Maguire e Braun (2016) ao entendermos que de certo modo este material representa conteúdos de política, quer seja pela tangibilidade do discurso dos integrantes do grupo focal e as singulares afetações que se lhes foram esculpidas, quer seja pela concretude documental e/ou visual do material proposto pelos agentes burocráticos imbricados no contexto da produção de texto político. Para os autores,

\footnotetext{
Políticas tornam-se representadas e traduzidas em e por meio de diferentes conjuntos de artefatos, experiências, recursos materiais e atividades durante o serviço; essas são as microtecnologias e as representações de política que servem como elaboradores de significado e controles de significados no mundo socialmaterial da escola. (BALL; MAGUIRE; BRAUN, 2016, p. 172).
}

Para dar conta dos conceitos explicitados anteriormente, o material empírico que fundamenta este trabalho foi coletado por meio de um Grupo Focal (BARBOUR, 2009) e por meio da Análise Documental (YIN, 2016). O grupo focal foi composto por cinco professoras: uma de Língua Portuguesa - Área de Linguagens, uma de Matemática - Área de Matemática, uma de Biologia e uma de Química - Área de Ciências da Natureza e uma de Matemática que à época atuava como vice-diretora no turno da manhã e supervisora pedagógica no turno da noite. Ressaltamos que todas elas participaram integralmente do processo de desenvolvimento do EMP entre os anos de 2011 a 2014.

A ambientação do grupo foi cuidadosa, realizada conforme descrito em Motta (2020) e o roteiro de discussão foi organizado com vinte e cinco questões distribuídas nos eixos redesenho curricular, práticas pedagógicas e expressão dos resultados escolares. Posteriormente foi realizada a transcrição do material, a partir de indicações recomendadas para essa técnica, sendo os sujeitos de pesquisa identificados com uma letra maiúscula. De posse desse corpus, realizamos o 
processo de unitarização e categorização, adotando como técnica a Análise Textual Discursiva (MORAES; GALIAZZI, 2013). Como resultado, obteve-se três categorias finais, uma das quais denominada Gestão Empresarial da Escola, que será desenvolvida na sequência desse trabalho.

Tentando dar conta da ideia que compreende o ciclo de políticas como algo fluido, aninhado, onde as práticas acontecem nos contextos de influência, de produção do texto e da prática escolar, nosso segundo campo de prospecção de material de pesquisa centrou-se na análise documental e teve por base a documentação recebida pela escola, via e-mail oficial. Enquanto agentes da

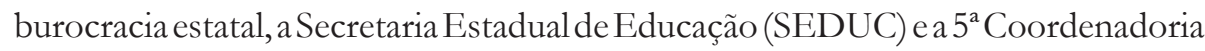
Regional de Educação ( $5^{a} \mathrm{CRE}$ ) são as entidades mais próximas do contexto da prática da escola estudada. Partilhamos com Araújo (2013) o entendimento da burocracia como um contexto da prática a ocorrer no espaço estatal, capaz de submeter a política a um processo de interpretação e recriação antes mesmo de chegar ao pátio das escolas. Foram selecionados documentos de outubro de 2011 a novembro de 2014, período de construção do EMP na escola, segundo a filosofia do Governo do Estado eleita para o ciclo 2010-2014. Como resultado, foram selecionados 101 documentos, tais como: memorandos circulares, convites para reuniões e formações, pareceres, convocações para gestores, regimentos, orientações avaliativas e procedimentais, listas de referenciais teóricos, alterações e retificações de datas de eventos, modelos de regimento escolar, matriz e grade curricular. Esses artefatos são oriundos, majoritariamente, da $5^{a} \mathrm{CRE}$, sob determinação e consonância da SEDUC. Tais fontes foram trabalhadas enquanto elementos de triangulação analítica na discussão das categorias analisadas.

\section{GESTÃO EMPRESARIAL, RECONSTRUÇÃO CURRICULAR E ATUAÇÃO}

Em muitas unidades de análise originadas do grupo focal, as professoras referenciam o fato de se perceberem, junto com a comunidade escolar, na condição de figurantes no processo de reconstrução da base curricular encaminhada a partir da política do EMP. Suas falas elencam ideias vinculadas a coisas prontas, protocolo, formalidade, participação burocrática, pouca valorização das especificidades locais, etc. Em outros momentos da dinâmica, afloraram questões ligadas à intensificação do trabalho, representada pelas noções de acumulação de papeis, de falta de tempo para formação e reuniões, de aumento da carga horária em sala de aula, de perdas profissionais etc. Esse conjunto de elementos discursivos, em consonância com outros da análise documental, aglutinaram-se em torno de questões de performatividade, desempenho e padronização externa 
imbricados nas mudanças do papel do Estado. As ideias manifestadas coadunam com um sentimento indicativo de que por vezes a escola perde visibilidade à sombra de modelos de gestão oriundos do meio empresarial e que, em tal condição, parece produzir certas dificuldades dos fazeres da esfera escolar, ante a legislação produzida com argumentos emprestados do mundo da iniciativa privada.

$\mathrm{Na}$ análise documental referente às comunicações entre os agentes burocráticos e a escola, os discursos contidos sugerem a operacionalização de uma voz de comando, por vezes apressada e, nesse sentido, em simbiose com o ambiente de investimentos privados, que exige retorno rápido. A relação entre o tempo necessário para a escola realizar determinados deslocamentos e o tempo da política parecem defasados.

Nesta seção, a partir das categorias intermediárias produzidas no processo de aplicação da ATD, abordaremos a questão específica do redesenho curricular no contexto da escola, o qual concluímos ter sido desenvolvido de acordo com a reconstrução burocrática do conhecimento e o silenciamento das vozes no contexto da prática, resultando numa atuação limitada das professoras no cenário escolar.

No documento orientador denominado Proposta Pedagógica para o Ensino Médio Politécnico e Educação Profissional Integrada ao Ensino Médio - 2011-2014, elaborado pela SEDUC/RS e datado entre outubro e novembro de 2011, encontramos alguns princípios fundamentais em relação às discussões da organização curricular do EMP, entre eles a divisão da grade curricular em dois blocos definidos como formação geral e parte diversificada. Integrando os dois blocos, está a figura da disciplina de seminário integrado, atuando como um catalisador por intermédio do desenvolvimento de projetos e sob a orientação de um coordenador pedagógico específico. A carga horária dessa disciplina seria ampliada em direção ao $3^{\circ}$ Ano, na medida em que os projetos ganhassem complexidade, elevando as necessidades de trabalho escolar para além do espaço de um turno. O conhecimento visto como processo de vivência, transitório e provisório, percebe o currículo como sendo

[...] o conjunto das relações desafiadoras das capacidades de todos, que se propõe a resgatar o sentido da escola como espaço de desenvolvimento e aprendizagem, dando sentido para o mundo real, concreto, percebido pelos alunos e alunas. Conteúdos são organizados a partir da realidade vivida pelos alunos e alunas e da necessidade de compreensão desta realidade, do entendimento do mundo (SEDUC, 2011, p. 15). 
Quando revisitamos os registros comunicativos entre a $5^{\mathrm{a}}$ CRE e a escola desde o início do ano de 2011, não encontramos orientações anteriores ao mês de outubro do referido ano. Como primeiro artefato, consta o um e-mail convidando o diretor e a supervisora para uma reunião no dia 07/10/2011, com o intuito de apresentar a Proposta de Reestruturação Curricular do Ensino Médio e Profissional. É interessante observar que não há aprofundamento na temática que será desenvolvida, restringindo-se ao uso do termo "orientações" de modo genérico. No dia 11/10/2011 temos o e-mail que apresenta textos para aprofundamento teórico, desde suportes legais e normativos até discussões para embasar a atuação dos professores, contendo dez anexos que juntos somavam 236 páginas a serem lidas, discutidas, contextualizadas e recontextualizadas pela escola em pleno desenrolar do último trimestre letivo.

Partindo do pressuposto da gestão democrática, a consolidação da política seria realizada por meio de Conferências. A Conferência Municipal, com a participação dos delegados eleitos na Conferência Escolar, é convocada para 07/11/2011, três semanas após o envio desses documentos, tempo no qual deveria ocorrer a apropriação teórica e a realização da Conferência Escolar. Quanto à Conferência Regional, sua realização ocorre em 17/11/2011 e a Conferência Inter-regional, sediada na cidade de Rio Grande/RS, registra-se no dia 05/12/2011.

Por sua vez, a temática referente à reconstrução curricular vai ser comunicada em Memorando Circular de 06/02/2012, acompanhado de anexo denominado "Regimento Referência em Politécnico". A providência legal para garantir a troca do Regimento se dá a partir do Parecer 156/2012, do Conselho Estadual de Educação, que orienta sobre o Ensino Médio e suas diretrizes. Entre prerrogativas básicas a respeito do Regimento Referência, destacamos:

[...] cumpre ressaltar que não substituirão de pleno os Regimentos Escolares aprovados e em vigor. Conforme projeto, servirão de complemento, durante 2012, aos Regimentos Escolares e referencial para a elaboração, durante este mesmo ano, dos novos textos regimentais das escolas. Sendo provisórios e passageiros [...] não se caracterizam como regimentos-padrão stricto sensu. [...].

O mérito dos "regimentos referência" consiste em explicitar a linha pedagógica a ser seguida pelas escolas estaduais. Neste sentido é de registrar que é competência da entidade mantenedora sinalizar a orientação a ser seguida por suas escolas, sem que com isso a autonomia pedagógica fique comprometida. [...]. (CONSELHO ESTADUAL DE EDUCAÇÃO. Parecer no 156/2012, fl. 6).

A organização curricular prevista para o funcionamento do EMP estava disposta no decorrer de $3.000 \mathrm{~h}(1.000 \mathrm{~h} / \mathrm{ano})$. Para a maioria das escolas, a forma mais viável de organização curricular incluía o trabalho em dois turnos, uma 
vez que o aumento de $1 \mathrm{~h}$ no turno de trabalho seria incompatível no contexto da prática. Em nossa escola, uma escola rural, os horários disponíveis para o transporte de alunos, professores e funcionários impediam qualquer acréscimo de tempo nos turnos, bem como o fato de que a maioria dos professores estavam vinculados a outras escolas. Outro grande desafio seria a organização do ensino noturno, composto por parte significativa de alunos trabalhadores, onde a alocação de carga horária obrigatória em turno inverso poderia contribuir para o aumento dos índices de evasão e retenção escolar.

Dentro dos possíveis cenários a serem construídos, operando em uma gama estreita de respostas criativas (BALL; MAGUIRE; BRAUN, 2016), o início do ano letivo de 2012 foi marcado pela pressão sobre o grupo de professores para a reconstrução da grade curricular. O e-mail da 5ª CRE de 02/03/2012 enfatiza a urgência da produção da nova estrutura do currículo. Em resposta, a coordenação pedagógica da escola encaminha no mesmo dia um texto de cinco (05) páginas que, entre as justificativas e as conclusões, aponta para a questão da pouca disponibilidade de tempo dos docentes para atuarem nas discussões pedagógicas. Percebe-se que a política do EMP no cenário escolar clama pelo aumento da produtividade dos sujeitos, quer materializar-se como influência, como texto e como discurso, disputa novo espaço uma vez que "Esses textos não podem ser simplesmente implementados! Eles têm que ser traduzidos a partir do texto para a ação - colocados em prática - em relação à história e ao contexto, com os recursos disponíveis." (Ibidem, p.14).

Assim, a coordenação pedagógica da escola assumiu o desenvolvimento

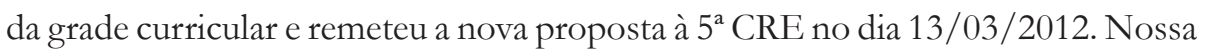
pesquisa documental encontrou um considerável lapso temporal entre essa data e o próximo contato para tratar de questões envolvendo o redesenho curricular, o qual ocorreu em 09/11/2012, quando solicitava que a escola refizesse apenas questões relativas à distribuição de percentuais de carga horária para a disciplina de seminário integrado no diurno e, para o noturno, permitia que o trabalho fosse desenvolvido em $800 \mathrm{~h}$ letivas anuais em atendimento às características geográficas e sociais da instituição. Apenas no dia 07/05/2013 aparece novo e-mail dando sequência aos planos de estudo e à grade curricular para o segundo ano de EMP e, em 13/12/2013, há outra mensagem da $5^{\text {a }}$ CRE na qual são disponibilizados para a escola os planos de estudo para 2013. Concluindo a busca em relação ao tema da reestruturação curricular, em 01/04/2014 a coordenação escolar envia os planos de estudo e a grade curricular para o terceiro ano do EMP, sendo essa a última referência de que dispomos. Como se pode observar, esta análise documental percorreu um intervalo de três (03) anos. 
$\mathrm{Na}$ sequência, discutiremos esse processo a partir da perspectiva das professoras que participaram do grupo focal descrito acima. Destaca-se que as falas lidam com memórias, com vivências sentidas que remontam os anos de 2011 a 2014, ou seja, estaremos manejando com resgates de memória de cinco (05) a oito (08) atrás e, desta feita, trabalhando com marcas mais significativas nos corpos dos sujeitos. A primeira discussão do grupo focal versa a respeito das atuações das professoras na construção do redesenho curricular dentro da política do EMP, focando nos componentes curriculares e nas possibilidades de atender às proposições da política. Nisso, uma das professoras expôs que

\begin{abstract}
Mas na verdade eu acho que não teve uma reconstrução. A gente adaptou muitos conteúdos depois dessa função aqui [do EMP]? Eu acho que não, a gente continuou e, de repente, tendo um enfoque diferente em função de ter alguns trabalhos que entravam em alguma disciplina específica, mas eu acho que não teve uma reconstrução do componente. A gente acabou seguindo uma grade comum que as escolas receberam, grade essa definida por alguém, e a gente só seguiu aquela grade. (S).
\end{abstract}

A percepção que brota dessas lembranças indica que a atuação, no contexto da escola, relacionada ao processo de reconstrução curricular das disciplinas, ocorreu sem muitos espaços para apropriação e reinterpretação criativa do texto da política. Quando a participante pergunta ao seu banco de memórias se teria havido adaptações (que seriam criações), a resposta aponta para uma tênue recontextualização ligada aos projetos dos alunos na disciplina de seminário integrado mas, em linhas gerais, enfatiza a ideia de padronização, de algo criado por alguém e que deveria ser seguido. Ao adotar a grade curricular feita por outros atores, em outra arena de atuação, notamos o predomínio do uso do modo imperativo nos tempos verbais das falas das professoras, o que nos permite inferir uma forte presença de discursos de agentes externos.

Outro aspecto escrito no texto da política do EMP, ainda no que se refere ao currículo, tratava da reconstrução curricular em função das áreas do conhecimento, ou seja, ampliar a ideia do conhecimento no sentido de buscar superar a relação parte-totalidade para promover uma atuação interdisciplinar. No documento base da SEDUC, encontramos:

O relacionamento das grandes áreas do conhecimento e dos saberes para a resolução de problemas não é propriamente uma novidade, mas a intencionalidade de ações nessa direção, no que diz respeito ao ensino, é recente. Advém do resgate de visões epistemológicas e práticas de pesquisa que trabalham o objeto em sua totalidade [...] (SEDUC, 2011, p. 19). 
Esse redesenho curricular relacionado às áreas de conhecimento e a consequente interdisciplinaridade é assim resgatado pela professora:

\begin{abstract}
Por área [de conhecimento] aí mesmo é que não, porque quem nunca deu seminário [aula de] nem sabia o que estava acontecendo. Só tinham conhecimento os professores da disciplina [de seminário integrado] e os professores da banca [convidados a avaliarem os projetos dos alunos no final do trimestre], mais ninguém. A gente até tentava apresentar no final para a escola, se tentou fazer, mas os professores que não eram daquele dia não iam. (R).
\end{abstract}

Nessa cena, o protagonismo da fala recai sobre o problema da maximização das cargas horárias em sala de aula, fator prático que impede muitos atores da política de participarem dessa parte do roteiro. A política do EMP enquanto texto, cercado de condições ideais, fantásticas e "febris" (BALL; MAGUIRE; BRAUN, 2016), choca-se com o contexto real enredado historicamente em sua conjuntura particular de escola do interior, emprestando requinte dramático à peça política atuada na caixa cênica da escola que depende do contexto, que depende das condições do palco simplesmente porque

[...] as políticas são colocadas em ação em condições materiais, com recursos variados, em relação a determinados "problemas". As políticas - novas ou antigas - são definidas contra e ao lado de compromissos, valores e formas de experiências existentes. [...]. Assim, o material, o estrutural e o relacional precisam ser incorporados na análise de política, a fim de compreender melhor atuações das políticas no âmbito institucional. (Ibidem, p. 37).

Assim, pode-se avaliar que a ausência ou o desconhecimento por parte do grupo de professores acerca dos acontecimentos escolares não se trata, necessariamente, de falta de comprometimento ou de profissionalismo. Há condições específicas, pontuais, particulares a esse ambiente que contribuem para atuações deste ou daquele jeito. Em sua cena isolada, em sua condição excelente, o texto político (do discurso à sua materialidade burocrática) resplandece carregado de harmonia até deslocar-se ao contexto da prática. Nesse espaço, a ideia de resgate epistemológico enreda-se na dificuldade de participação dos profissionais, imposta por condições fora de seus domínios. Mesmo que o texto da política assuma que "A interdisciplinaridade é um processo e, como tal, exige uma atitude que evidencie interesses por conhecer, compromisso com o aluno e ousadia para tentar o novo em técnicas e procedimentos" (SEDUC, 2011, p. 19), cabe perguntar: será que os professores que não podiam participar da apresentação dos alunos no seminário integrado estavam desinteressados pelo conhecimento? Faltou-lhes ousadia para ajustarem sua carga horária? Onde estaria, por parte dos órgãos gestores, a ousadia e o compromisso com alunos? 
Defendemos que houve uma reconstrução burocrática do conhecimento no contexto da prática da escola, com atuação limitada das professoras, embasados em algumas das sensações descritas em nosso referencial da teoria da atuação, segundo o qual:

Nossos dados tomados como um todo transmitem uma sensação de sobrecarga
e contradição sendo realizada em conjunto por estruturas frágeis, narrativas
mais ou menos convincentes e uma grande dose de compromisso cru (de alguns
diferentes tipos e graus, para estudantes e para escolas) e muito boa vontade. [...].
Uma grande parte do que se passa nas escolas em termos de atuação da política
é a "configuração" e a reconfiguração" do trabalho. Este visa manter a
durabilidade da instituição em face dos efeitos desestabilizadores do contexto, da
mudança e da política. (BALL; MAGUIRE; BRAUN, 2016, p. 102, grifo nosso).

Observando o redesenho curricular sob o prisma da configuração e reconfiguração (BALL; MAGUIRE; BRAUN, 2016), passamos a análise das vozes no contexto da prática. Uma das definições contidas no documento base quanto à etapa escolar dizia que "É necessário que sejam escolhidos delegados que representem cada um dos segmentos participantes" (SEDUC, 2011, p. 33), indicando no texto da política que o discurso interno seria considerado durante o processo de construção do EMP. Em relação ao tratamento dispensado às vozes da comunidade escolar na Etapa Municipal, a participação dos delegados foi assim descrita na voz da professora:

Só que eu lembro que, por exemplo, se o pai ou o aluno chegasse com uma questão que divergia do pensamento deles [organizadores da conferência municipal] já cortavam, lembra! Diziam que "não dá tempo agora gente, a gente discute numa próxima" só que a próxima nunca veio. E depois na mídia passou isso, que foi feito com a participação de todo mundo, mas não. (A).

A ideia da construção do EMP a partir da realização de conferências públicas e participativas é indicativo de que o contexto escolar teria um peso importante na construção da política, enquanto voz ativa e repleta de sonoridade: pais, alunos e professores, expressando suas posições para o coletivo, o que aponta um avanço democrático na relação da política com a arena à qual se destina. Mas a partir do que se discutiu até aqui a respeito dessa reconstrução curricular, o resgate que surge daqueles momentos transfere ao processo uma sensação ambígua, entrega uma conotação de peça publicitária direcionada aos meios de comunicação social, como se a participação da coletividade fosse apenas instrumento a legitimar a própria política ante a sociedade. 
Ao analisarmos as falas das professoras, a participação popular adquire uma tonalidade opaca, acaba enfraquecida ao ser colocada lado a lado com expressões como protocolo e formalidade, corroborando novamente com a noção de tática da política e seus instrumentos de validação. Da etapa da conferência municipal em 2011 brotam memórias:

Eu lembro de vir num encontro, foi no auditório do Pelotense. Estavam ali alguns alunos. O que é que me pareceu ali: várias escolas, professores, alunos e pais, tudo meio que tinham que fazer aquilo ali para mostrar que pediram a opinião, que eles [comunidade] estavam no contexto. (F).

Outro ponto importante nesta análise a respeito das vozes internas é aquele que encaminha para as questões relativas à participação familiar na construção do conhecimento a que se propunha política, sobretudo no seu plano de metas para a jornada do ensino médio. No plano de metas, consta a "Ressignificação do Ensino Médio Politécnico e Ensino Médio - Curso Normal, através da reestruturação curricular, de 2012 a 2014" (SEDUC, 2011, p. 29). Para tal evento, que se pode considerar ambicioso, a participação da comunidade em seu segmento de pais e alunos deveria compor o processo de construção para além dos momentos destinados aos encontros representativos das conferências e se efetivar num movimento constante de escuta dos sujeitos aos quais os serviços escolares se destinam. Embora esta pesquisa não tenha se dirigido a prospectar elementos narrativos por parte do segmento de pais e alunos, uma das professoras que atuaram esta política considera que

Nessa questão, se foram atendidas as famílias, tu pensa que uma escola do interior, se tu fosses falar com as famílias, com certeza eles iriam pedir mais ciências da natureza, porque há uma questão ligada a terra [produção ligada à agricultura familiar]. E não foi isso que teve, essa discussão a respeito do que seria preferido ou o que valeria mais a pena para eles no caso. (A).

Portanto, sem o devido tempo para tornar a discussão profícua a ponto de se criar um currículo identificado com a comunidade, a ressignificação estaciona, transita sobre a participação popular como instrumentalização a justificá-la em sua reconstrução burocrática, provoca uma esperança de parceria que não se vê efetiva no contexto da prática. De algum modo podemos inferir que essa promessa de participação da comunidade escolar, ao esvaziar-se no desenrolar da peça política, pode ter ampliado ao tempo presente alguns efeitos que se traduzem em certa relativização do papel educativo das famílias na formação dos jovens. Ao não cumprir a promessa de ressignificação coletiva a que se propunha, a atuação da política deixa marcas nos corpos dos sujeitos uma vez que "As políticas são 
repletas de emoções e de tensões psicossociais. Elas podem ameaçar ou perturbar a autoestima, o propósito e a identidade." (BALL; MAGUIRE; BRAUN, 2016, p. 21). Desse mosaico de sensações, a decepção parece fazer-se presente na comunidade escolar quando outra professora constata que hoje

No Médio os pais já não vão tanto [...]. E cada vez mais, menos pais na escola, como na última reunião de boletins. Numa turma vieram dois pais, na outra não veio ninguém! (F).

Deste exercício reflexivo, onde procuramos problematizar a respeito da condução da reconstrução curricular e da abordagem das vozes internas a partir de atuações imbricadas a modelos de gestão empresarial, enfatizando controle e persuasão, o novo emergente aponta que mesmo submetidas a alinhamentos e restrições, a atuação das professoras nesse contexto de conformação a demandas externas é uma forma de atuação política, mais ou menos limitada pelo processo de construção da política entre seus movimentos de interpretação e de tradução.

O cenário sobre o qual este artigo se debruça articula-se melhor ao movimento de interpretação do texto político, instante em que o contexto escolar possui poucos atores - a maioria ligados à gestão - que apresentam certo grau de intimidade, de compreensão, de decodificação e de engajamento em relação aos ajustamentos solicitados pelos agentes burocráticos externos. Considerando a interpretação como "um processo de explicação, esclarecimento e criação de uma agenda institucional” (BALL; MAGUIRE; BRAUN, 2016, p. 69), quer dizer, é a hora de convencer a equipe de trabalho em relação aos fundamentos e aos valores narrados pelo texto político, as professoras encontram-se limitadas em suas capacidades criativas de recontextualização da política porque não é esse ainda o ato destinado à recodificação, à construção de artefatos, à materialização do texto político em suas práticas.

Logicamente, o ato da tradução da política, que começa a ser operacionalizado a partir de conversas, eventos, reuniões formais e informais, observações de aulas, modelos profissionais etc., poderá ampliar as possibilidades criativas das professoras e professores. Ainda assim, nessa parte da encenação, a criatividade estará limitada pelos valores institucionalizados, pelas escolhas realizadas durante o processo inicial de interpretação do texto.

Portanto, inferimos que as professoras tiveram sua atuação bastante limitada, com poucas possibilidades para encenações criativas da política no que se refere à reconstrução do currículo escolar e ao estabelecimento de instrumentos capazes de atender às vozes da comunidade escolar, principalmente pela falta de espaço-tempo para a realização desses processos que se apresentam complexos e abrangentes. 


\section{CONSIDERAÇÕES FINAIS}

Da análise documental originada da comunicação entre os órgãos gestores e a escola, avaliamos que se constituiu uma relação impregnada de características correlatas ao modelo gerencialista, sobretudo no que diz respeito à apresentação da política à comunidade escolar, bem como ao processo instaurado na reconstrução curricular que embasava a ideia de uma mudança significativa a ser conquistada pelo EMP. Embora houvesse nos documentos elaborados pelo governo da época, notadamente de vertente progressista, elementos discursivos opostos aos formatos empresariais de controle, de responsabilização e de desempenho, inferimos que o tratamento aos sujeitos atores da política esteve ajustado, contraditoriamente, aos regimes corporativos criticados, representados por fatores tais como: a sobrecarga de trabalho, a participação da comunidade como mero construto narrativo de democratização da escola, o sentimento de desvalorização do trabalho docente, entre outros. Em nossa perspectiva, esse enredo dicotômico entre os sentidos externos e os sentidos internos da política percebidos no contexto da prática, exigem uma gama de competências complexas aos atores de política que as arenas de influência e de produção de texto pouco consideram, talvez porque suas responsabilidades conjunturais não pretendem mesmo dar conta destas questões.

Quando discorremos a respeito da atuação das professoras como algo limitado, restrito, ressaltamos que, ainda assim, tal limitação consiste em uma forma de atuação da política. $O$ texto político, ao impelir os sujeitos a executarem movimentos apressados, intermitentes, caóticos, tornando-lhes exíguo o tempo destinado à construção do processo segundo necessidades do contexto, conta desde sua arena de produção com certa tecnologia de controle e persuasão a restringir os espaços de criação coletiva. De modo singular, o controle do tempo apresenta-se como uma eficaz ferramenta de gestão que se movimenta do meio empresarial e alcança o contexto escolar.

Ao finalizar este trabalho, reafirma-se a complexidade que a política assume no contexto escolar, sua arena de atuação mais diversa, indicando o quão híbrido pode se tornar o texto político ao ser encenado por uma diversidade de atores marcados por trajetórias e expectativas de vida diferentes. As interações e as acomodações necessárias na representação da política corroboram ser pouco produtiva a arguição linear, imprimindo à análise localizada e singular um importante espectro de produção de conhecimento do campo, uma vez que o sentido da política pode variar de forma significativa segundo o contexto, conforme se procurou evidenciar. 


\section{REFERÊNCIAS}

ARAÚJO, Jair. Novos sentidos das políticas curriculares para a educação profissional no Instituto Federal Sul-Rio-Grandense. 2013. Tese (Programa de Pós-Graduação em Educação da Faculdade de Educação) - Universidade Federal de Pelotas, 2013.

BALL, Stephen. Education reform: a critical and post-structural approach. Buckingham: Open University Press, 1994.

BALL, Stephen. Performatividade, privatização e o pós-estado do bem-estar. Educação \& Sociedade, Campinas, v. 25, n. 89, p. 1105-1126, set./dez. 2004.

BALL, Stephen. Profissionalismo, gerencialismo e performatividade. Cadernos de pesquisa, v. 35, n. 126, p. 539-564, set./dez. 2005.

BALL, Stephen. O que é política? Textos, trajetórias e caixas de ferramentas. [Título original: What is policy? Texts, trajectories and toolboxes]. In: BALL, S. J. (Ed.). Education Reform: a critical and post-structural approach. Traduzido por: Joice Elias Costa, 2006. cap. 2, p.10-17.

BALL, Stephen. MAINARDES, Jefferson. Políticas Educacionais: questões e dilemas. São Paulo: Cortez, 2011, 288p.

BALL, Stephen; MAGUIRE, Meg; BRAUN, Annette. Como as escolas fazem as políticas: atuação em escolas secundárias. Ponta Grossa: Ed. UEPG, 2016.

BARBOUR, Rosaline. Grupos focais. Porto Alegre: Artmed, 2009.

BOWE, Richard; BALL, Stephen; GOLD, Anne. Reforming education \& changing schools: case studies in policy sociology. London: Routledge, 1992.

JAKIMIU, Vanessa. Políticas de reestruturação curricular no ensino médio: uma análise do programa ensino médio inovador. 2014. Dissertação (Curso de Pós-Graduação em Educação, na linha de pesquisa Políticas Educacionais do Setor de Educação) - Universidade Federal do Paraná, 2014.

MOREIRA, Antônio. Currículos e Programas no Brasil. 13 $3^{\mathrm{a}}$ Ed. Campinas: Editora: Papirus, 2006. 236p. 
MORAES, Roque; GALIAZZI, Maria do Carmo. Análise textual discursiva. 2 ed. rev. Ijuí: Ed. Unijuí, 2013.

MOTTA, Henri. A política do ensino médio politécnico em três atos: reconstrução curricular, práticas pedagógicas e expressão dos resultados. 2020. Dissertação (Programa de Pós-Graduação em Educação) - Instituto Federal Sulrio-grandense/Câmpus Pelotas, 2020.

PICOLI, Elaine. Programa ensino médio inovador: um estudo sobre a política de flexibilização curricular. 2016. Dissertação (Programa de Pós-Graduação em Educação) - Universidade Estadual de Maringá, 2016.

SEDUC/RS. Proposta pedagógica para o ensino médio politécnico e educação profissional integrada ao ensino médio 2011-2014. Disponível em: https://servicos.educacao.rs.gov.br/pse/html/ens_medio.jsp?ACAO=acao1. Acesso em: 30 mai. 2018.

SEDUC/RS. Regimento referência das escolas de ensino médio politécnico da rede estadual 2012. Disponível em https://servicos.educacao.rs.gov.br/pse/ html/ens_medio.jsp?ACAO=acao1. Acesso em: 30 mai. 2018.

YIN, Robert. Pesquisa Qualitativa do Início ao Fim. Tradução de Daniela Bueno. Porto Alegre, RS: Penso, 2016.

\footnotetext{
Henri de Leão Motta

Graduado (UFPel) em Licenciatura Plena em Geografia, há 20 anos professor de Ensino Fundamental e Médio das Redes Municipal e Estadual do Município de Pelotas/RS, especialista (UFPel) em Políticas Públicas para Educação. Mestrando do Programa de Pós-Graduação em Educação (PPGEdu) ligado ao Mestrado Profissional em Educação e Tecnologia (MPET) do Instituto Federal Sul-riograndense (IFSul), campus Pelotas. Pesquisador do Grupo de Pesquisa Políticas Educacionais em Contexto (IFSul).E-mail: henri081970@gmail.com
} 
Jair Jonko Araujo

Graduado (UFPel) e mestre (UFRGS) em Ciência da Computação, com Doutorado em Educação (UFPel). Professor Titular do Instituto Federal Sul-rio-grandense (IFSul). Participa do CEPE/UFPel (Centro de Estudos em Políticas Educativas e dos Grupos de Pesquisa Políticas Educacionais em Contexto (IFSul) e Gestão, Currículo e Políticas Educativas (UFPel). Desenvolve estudos em políticas educacionais e curriculares, processos de gestão e avaliação educacional e seus desdobramentos em diferentes áreas educacionais com aporte, preferencialmente, de autores pós-estruturalistas. E-mail: jair.jonko@gmail.com

Recebido em 27/06/2020

Aprovado em 30/09/2020 